\title{
The corrosion wear behaviors of Hastelloy C276 alloy in seawater
}

\author{
Chen Jun ${ }^{1,2, *}$ \\ ${ }^{1}$ School of Materials Science and Engineering, Henan University of Science and Technology, Kai \\ Yuan Road, Luoyang, China \\ ${ }^{2}$ Collaborative Innovation Center of Nonferrous Metals, Kai Yuan Road, Luoyang, China \\ a chenjun318822200@163.com \\ *corresponding author
}

Keywords: Corrosion; Wear; Hastelloy C276 alloy; Seawater.

Abstract. The aim of this paper is to study the corrosion wear behaviors of Hastelloy C276 alloy sliding against AISI 316 stainless steel in artificial seawater and distilled water. The electrochemical properties of this alloy are measured by potentiodynamic polarization method. The corrosion wear properties have been evaluated by an MRH-03 type ring-onblock test rig in artificial seawater with different salinity. The wear loss can be measured by the difference of weight before and after corrosion wear tests. The results show that the typical passivation behavior can be found for Hastelloy C276 alloy in seawater. The Hastelloy C276 alloy has the lowest corrosion current density in $3 \%$ seawater, which can be attributed to the synergism of salt concentration and dissolved oxygen. The friction coefficients are in general larger in distilled water compared with seawater. The wear loss in seawater is always higher than that in distilled water. Seawater can reduce friction coefficient and wear resistance.

\section{Introduction}

Owing to the high resistance to pitting and crevice corrosion, the Nickel based alloys are widely used in many fields such as chemical industry (heat-exchangers, pumps, vessels and pipes), marine industry (valves, pumps, impellers and other kind of equipment), power generation and the automotive industries[1-3]. Although these alloys have excellent corrosion-resistance owing to the protective properties of surface oxide film, they are sensitive to fatigue and wear. For the passive metals, they are usually susceptible to corrosion-wear. Mechanical wear can easily destroy the protective passive film, resulting in the high corrosion rate before surface repassivates[4-5].

Most of the tribocorrosion studies in the literature have been focused on the study of passive alloys, such as stainless steels, Ti and its alloys and aluminum alloys. Over the last years, many studies have been undertaken on the corrosion resistance of Nickel alloys in different environments. On the other hand, fewer studies of their tribological properties and their tribocorrosion behavior were available in the literature. On considering the counterpart materials, alumina and zirconia were used in previous literatures. Due to the inert property and high hardness of ceramic materials, it was 
simple to evaluate the tribocorrosion behavior of passive alloys. However, the ceramic materials have poor plasticity and low machinability performance[6-8]. It is rarely used in bearing system, precision instruments and orthopaedic implants. Passive alloys frictional pairs are wildly used compared with metal-alumina frictional pairs. However, the tribocorrosion properties of passive metals sliding each other in corrosion mediums have not yet been investigated in detail.

The purpose of this research focused on the effects of the seawater on the friction process of passive alloys. Hastelloy $\mathrm{C} 276$ was a high strength and high corrosion resistant $\mathrm{Ni}-\mathrm{Cr}$ alloy due to its inherent resistance to a variety of severe corrosive environments. The counterpart materials were AISI316 stainless steel, which was a passive metal widely used in the field of marine. The corrosion wear behaviors of Hastelloy C276 alloy sliding against AISI 316 steel in artificial seawater and distilled water were performed.

\section{Experimental}

The nickel based alloy Hastelloy $\mathrm{C} 276$ alloy with the composition of $16 \% \mathrm{Cr}, 16 \% \mathrm{Mo}, 5 \% \mathrm{Fe}$, $4 \% \mathrm{~W}, 2.5 \% \mathrm{Co}, 1 \% \mathrm{Mn}, 0.35 \% \mathrm{~V}, 0.08 \% \mathrm{Si}, 0.01 \% \mathrm{C}$, balance $\mathrm{Ni}$ is selected as the research material and AISI 316 stainless steel with the composition of $17.2 \% \mathrm{Cr}, 10.2 \% \mathrm{Ni}, 2.1 \% \mathrm{Mo}, 0.04 \%$ $\mathrm{C}$, balance $\mathrm{Fe}$ is the counterpart materials. And Table 1 shows the mechanical properties of the two metallic alloys. The corrosion wear behaviors of these alloys have been evaluated by an MRH-03 type ring-on-block test rig. And the upper block sample with the size of $19 \times 12 \times 12(\mathrm{~mm})$ is made of Hastelloy C276 alloy. The lower ring sample with the size of $\varnothing 49.22 \times 13.06(\mathrm{~mm})$ is made of AISI 316 stainless steel. And the rotation speed of the corrosion wear test is $200 \mathrm{rpm}$ with a linear velocity of $0.5 \mathrm{~m} / \mathrm{s}$. The normal load during the corrosion wear test is $100 \mathrm{~N}$. The experimental time of the corrosion wear is $60 \mathrm{~min}$. Before the corrosion wear test, both the upper and lower metallic samples are abraded to reach a surface roughness of $0.10 \mu \mathrm{m}$. Then the two samples are ultrasonically cleaned with acetone. And the aqueous medium lubrication can be made by continuously dropping medium onto sliding surface at the rate of about 300 drops per minute. During corrosion wear test, the friction coefficients can be measured directly from the tribometer and the wear volume loss $V$ of the blocks can be obtained by the following equation,

$$
V=\left(m_{0}-m_{1}\right) / \rho
$$

where $V$ is the wear volume loss of the metallic alloy $\left(\mathrm{mm}^{3}\right), \rho$ is density of the alloy, $m_{0}$ is the weight of metallic alloy before corrosion wear test $(\mathrm{mg})$, and $m_{1}$ is the weight of metallic specimen after corrosion wear test (mg). The mediums used in this study are distilled water and artificial seawater. And the seawater have been prepared according to ASTM D 1141-98 standard. Table.2 shows the composition of the seawater, where the gross concentration employed in the standard is an average of many reliable individual analyses and the concentration of the seawater was $3.5 \%$. To evaluate the effect of salt concentration on corrosion wear behaviors, $0.5 \%, 1 \%, 2 \%, 3 \%$ and $4 \%$ seawater are prepared by adjusting all the compounds in accordance with the mass fraction shown in Table 2. The $\mathrm{pH}$ values of all seawater solutions are adjusted to 8.2 using $0.1 \mathrm{~N} \mathrm{NaOH}$ solution. Electrochemical measurements have been carried out at room temperature using a CHI760C electrochemical test system with three-electrode cell. The Hastelloy C276 alloy specimen is working electrode. A platinum plate and saturated calomel electrode (SCE) are used as the counter and reference electrodes, respectively. A dynamic scan from $-2 \mathrm{~V}$ to $1.5 \mathrm{~V}$ (SCE) at a potential scanning rate of $0.1 \mathrm{mV} / \mathrm{s}$ is performed. Potentiodynamic polarization curves were automatically acquired. 
Table 1 Mechanical properties of Hastelloy C276 alloy and AISI 316 stainless steel.

\begin{tabular}{|c|c|c|c|}
\hline Materials & Young's $(\mathrm{GPa})$ & Hardness(HBS) & Tensile strength (MPa) \\
\hline Hastelloy C276 & 199 & 241 & 950 \\
\hline AISI 316 steel & 200 & 187 & 620 \\
\hline
\end{tabular}

Table 2 Chemical composition of $3.5 \%$ seawater.

\begin{tabular}{|c|c|}
\hline Compound & Concentration $(\mathrm{g} / \mathrm{L})$ \\
\hline $\mathrm{NaCl}$ & 24.53 \\
\hline $\mathrm{MgCl}_{2}$ & 5.20 \\
\hline $\mathrm{Na}_{2} \mathrm{SO}_{4}$ & 4.09 \\
\hline $\mathrm{CaCl}_{2}$ & 1.16 \\
\hline $\mathrm{KCl}$ & 0.695 \\
\hline $\mathrm{NaHCO}_{3}$ & 0.201 \\
\hline $\mathrm{KBr}_{3}$ & 0.101 \\
\hline $\mathrm{H}_{3} \mathrm{BO}_{3}$ & 0.027 \\
\hline $\mathrm{SrCl}_{2}$ & 0.025 \\
\hline $\mathrm{NaF}$ & 0.003 \\
\hline
\end{tabular}

\section{Results and discussions}

Fig. 1 showed the typical potentiodynamic polarization curves of Hastelloy C276 alloy in 3.5\% seawater can be found in Fig.2. It can be seen that the passivation behavior can be found for the alloy. Four different domains can be found, the cathodic domain includes potentials below $-1 \mathrm{~V}$ where the current is determined by the reduction of water and, partially, of dissolved oxygen. The domain between $-1 \mathrm{~V}$ and $-0.6 \mathrm{~V}$ can be characterized by transition from cathodic to anodic current at the corrosion potential. A large passive zone can be found between $-0.6 \mathrm{~V}$ and $0.9 \mathrm{~V}$, where the current density is approximately constant. Finally, in the transpassivity domain, an increase in the current density can be found at $1.0 \mathrm{~V}$, due to the oxidation of water. To confirm the corrosion rate of the alloy in seawater with different salinity, the potentiodynamic polarization curves have been completed from $-0.5 \mathrm{~V}$ to $-0.25 \mathrm{~V}$. Fig. 2 exhibits the potentiodynamic polarization curves of with different salinity. The corrosion potential $\left(E_{\text {corr }}\right)$, corrosion current densities (Icorr), anodic and cathodic Tafel slopes $\left(\beta_{\mathrm{a}}\right.$ and $\left.\beta_{\mathrm{c}}\right)$ are listed in Table 3. It can be found that the corrosion current density is $1.293 \mu \mathrm{Acm}^{-2}$ in $0.5 \%$ seawater and increased to $1.586 \mu \mathrm{Acm}^{-2}$ in $3 \%$ seawater and then decreased to $1.505 \mu \mathrm{Acm}^{-2}$ in $4 \%$ seawater. These results can be indicated that the alloy has the maximum corrosion rate in $3 \%$ seawater.

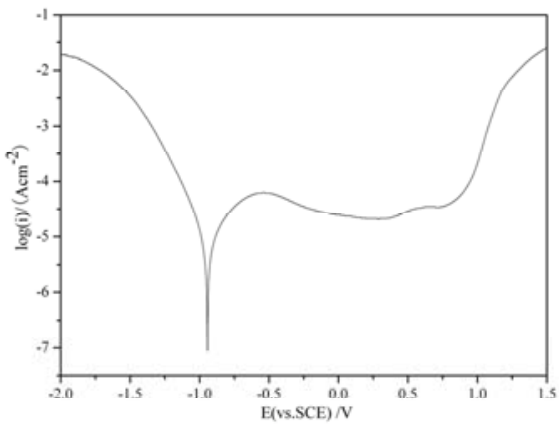

Figure 1 The typical potentiodynamic polarization curves of Hastelloy C276 alloy. 
The typical evolution of the friction coefficient with time have been shown in Fig. 3 for the cases of sliding tests in $3.5 \%$ seawater and distilled water. The friction coefficients rapidly reached a steady state value exhibiting some peaks at fairly regular time intervals. Such fluctuations can be attributed to the formation and ejection of wear debris. Moreover, less fluctuation can be observed in seawater. Friction coefficients are in general larger in distilled water compared with seawater. Corrosion mediums have antifriction effect in the tribocorrosion process. Fig. 4 exhibits the wear loss of Hastelloy C276 and AISI 316 steel sliding in different mediums. It can be seen that the wear loss in seawater was always higher than that in distilled water for both alloys. Such trend of results, strongly suggested that seawater could reduce the friction coefficient and the wear resistance. The AISI 316 stainless steel was less resistant to sliding damage than the Hastelloy C276 alloy. For Hastelloy C276 alloy, the wear loss was $0.585 \mathrm{~mm}^{3}$ in distilled water and increased to a maximum $3.273 \mathrm{~mm}^{3}$ in $3 \%$ seawater and then decreased to $2.852 \mathrm{~mm}^{3}$ in $4 \%$ seawater. It can be concluded that seawater salinity significantly influenced the wear loss. Such phenomena were attributed to the maximum corrosion rate in 3\% seawater. High corrosion rate resulted in large wear loss in corrosion wear condition.

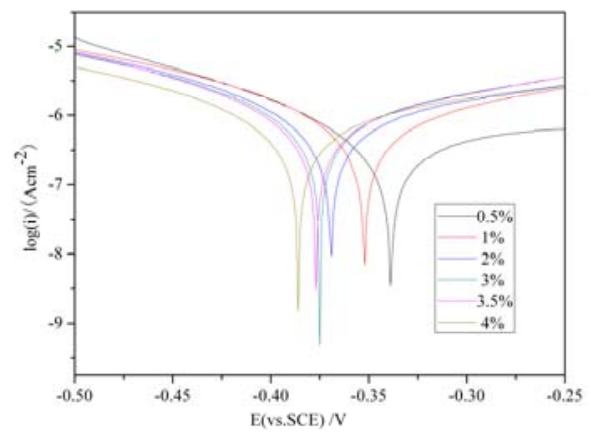

Figure 2 The potentiodynamic polarization curves of with different salinity.

Table 3 Corrosion parameter values of Hastelloy C276 alloy by Tafel plot analyses.

\begin{tabular}{|l|l|l|l|l|}
\hline Seawater & $E_{\text {corr }}(\mathrm{V})$ & $I_{\text {corr }}\left(\mu \mathrm{Acm}^{-2}\right)$ & $\beta_{a}\left(\mathrm{mVdec}^{-1}\right)$ & $\beta_{c}\left(\mathrm{mVdec}^{-1}\right)$ \\
\hline $0.5 \%$ & -0.336 & 1.293 & 7.622 & 2.751 \\
\hline $1 \%$ & -0.346 & 1.361 & 6.765 & 4.970 \\
\hline $2 \%$ & -0.362 & 1.461 & 6.971 & 3.682 \\
\hline $3 \%$ & -0.377 & 1.586 & 6.684 & 5.162 \\
\hline $3.5 \%$ & -0.379 & 1.541 & 7.051 & 5.005 \\
\hline $4 \%$ & -0.385 & 1.505 & 6.665 & 4.935 \\
\hline
\end{tabular}

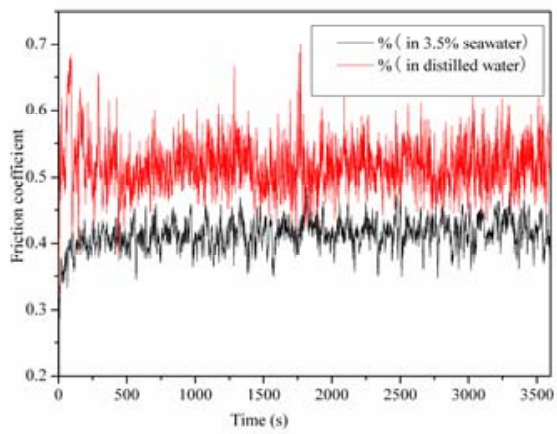

Figure 3 The typical evolution of the friction coefficient with time. 
In the corrosion wear process, wear can remove passive film and bare metal surface can be exposed to seawater. Corrosion can be accelerated due to the mechanical removal of a surface film that exposes the bare material to the electrolyte, leading to the onset of corrosion of the bare material. To investigate the synergism ratio between corrosion and wear, the synergism $\Delta V$ can be calculated. The contribution of $V_{\mathrm{c}}$ (wear loss induced by pure corrosion in the absence of wear), $V_{\mathrm{w}}$ (wear loss in pure water without corrosion) and $\Delta V$ to total wear loss, $V$, of Hastelloy $\mathrm{C} 276$ alloy in seawater are summarized in Table 4.

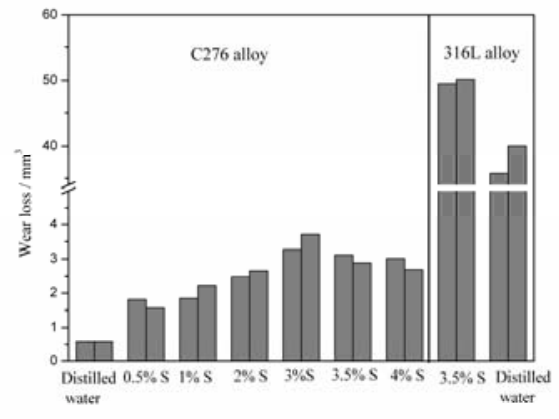

Figure 4 The wear loss of Hastelloy C276 and AISI 316 steel sliding in different mediums.

It can be seen that all the contributions of $V c / V$ are very small, which indicate that pure corrosion in the absence of wear is negligible for Hastelloy C276 alloy in seawater. Hastelloy C276 alloy has good corrosion resistance in seawater. The contributions of $V w / V$ and the $\Delta V / V$ are significant, indicating that wear loss is induced by mechanical abrasion and synergism action between corrosion and wear. Interestingly, the synergism action between corrosion and wear is related to the corrosion rate and with the increase of corrosion rate, the synergism $\Delta V$ become more important. A likely reason for this is the synergism $\Delta V$ is controlled by the electrochemical reactions in the corrosion wear process. It indicates that the corrosion of seawater has obviously accelerated the wear, even went to highest $86 \%$.

Table 4 Contribution of each parameter to wear loss of Hastelloy C276 alloy.

\begin{tabular}{|l|l|l|l|}
\hline Seawater & $V_{c} / V\left(\times 10^{-4}\right)$ & $V_{w} / V$ & $\Delta V / V$ \\
\hline $0.5 \%$ & 2.161 & 0.275 & 0.7248 \\
\hline $1 \%$ & 1.891 & 0.2285 & 0.7713 \\
\hline $2 \%$ & 1.607 & 0.1809 & 0.8189 \\
\hline $3 \%$ & 1.262 & 0.131 & 0.8689 \\
\hline $3.5 \%$ & 1.447 & 0.1545 & 0.8454 \\
\hline $4 \%$ & 1.497 & 0.1637 & 0.8362 \\
\hline
\end{tabular}

\section{Conclusions}

The tribocorrosion behaviors of Hastelloy C276 alloy sliding against AISI 316 stainless steel were investigated using a ring-on-block test rig in artificial seawater and distilled water. The following conclusions can be drawn:

Hastelloy C276 alloy has the maximum corrosion rate in 3\% seawater. The friction coefficient is larger in distilled water compared with seawater. The wear loss in seawater is always higher than that in distilled water for both the Hastelloy C276 and AISI 316 alloys. Such trend of results, strongly suggest that seawater could reduce the friction coefficient and the wear resistance. The AISI 316 stainless steel is less resistant to sliding damage than the Hastelloy C276 alloy. 


\section{Acknowledgements}

The research is financially supported by the National Natural Science Foundation of China (Grant No. U1604130).

\section{References}

[1] Stemp, M., Mischler, S. and Landolt, D. (2003) The effect of contact configuration on the tribocorrosion of stainless steel in reciprocating sliding under potentiostatic control. Corrosion Science, 45, 625-640.

[2] Espallargas, N. and Mischler, S. (2010) Tribocorrosion behaviour of overlay welded Ni-Cr 625 alloy in sulphuric and nitric acids: Electrochemical and chemical effects. Tribology International, 43, 1209-1217.

[3] Ramesh, R. and Gnanamoorthy, R. (2006) Development of a fretting wear test rig and preliminary studies for understanding the fretting wear properties of steels. Materials \& Design, 27, 141-146.

[4] Panda, B., Balasubramaniam, R., Mahapatra, S. and Dwivedi, G. (2009) Fretting and fretting corrosion behavior of novel micro alloyed rail steels. Wear, 267, 1702-1708.

[5] Ding, H., Zhou, G., Dai, Z., Bu, Y. and Jiang, T. (2009) Corrosion wear behaviors of 2024Al in artificial rainwater and seawater at fretting contact. Wear, 267, 292-298.

[6] Mischler, S. (2008) Triboelectrochemical techniques and interpretation methods in tribocorrosion: A comparative evaluation. Tribology International, 41, 573-583.

[7] Liu, F. B., Wang, J. D., Chen, D. R., Xu, Y. J. and Zhao, M. (2010) The Cavitation Erosion of the 45\# Carbon Steels Implanted with Titanium and Nitrogen. Tribology Transactions, 53, 239-243.

[8] Hiromoto, S. and Mischler, S. (2006) The influence of proteins on the fretting-corrosion behaviour of a Ti6Al4V alloy.Wear, 261, 1002-1011. 